\title{
(Será Que) Ninguém Pode Servir a Dois Senhores? 0 Dilema da Ecofood
}

\section{(Is That) No One Can Serve Two Lords? The Ecofood's Dilemma}

\author{
Carlos Eduardo de Lima \\ Fundação Getulio Vargas - FGV EAESP - Brasil \\ carloseduardodelima@gmail.com \\ ORCID: 0000-0001-7518-499X \\ Raul Beal Partyka \\ Fundação Getulio Vargas - FGV EAESP - Brasil \\ raul.partyka@fgv.edu.br \\ ORCID: 0000-0001-7941-2152 \\ Jailson Lana \\ Universidade do Vale Do Itajaí - UNIVALI - Brasil \\ jailson.lana@univali.br \\ ORCID: 0000-0003-0944-9667
}

Submetido em 23/10/2020; Aprovado em 15/03/2021.

\begin{abstract}
Resumo
Contexto: A Ecofood é uma plataforma de redistribuição de alimentos que tem como objetivos reduzir o desperdício de alimentos no planeta e combater a fome e a emissão de gases poluentes. Isso é feito, viabilizando a aquisição de comida excedente, porém de excelente qualidade, a preços reduzidos, através de um aplicativo. Objetivos de ensino: 0 caso possibilita compreender o processo de expansão de plataformas digitais do setor de alimentação e como negócios de impacto podem gerar vantagens para todas as partes interessadas. Fontes de dados: 0 caso demonstra uma empresa real que passa por um acelerado processo de crescimento. Seus idealizadores e gestores começam a discutir e problematizar acerca da expansão. 0 caso foi elaborado através de fontes primárias e secundárias. Os nomes dos sócios e da empresa se mantiveram fiéis. Contribuições: Do ponto de vista social, reduzir o desperdício de alimentos fortalece o combate à fome e aumenta a segurança alimentar. Por outro lado, é preciso mostrar e realizar que é possível ter ótimos ganhos financeiros ao diminuir as perdas que ocorrem com alimentos, neste caso em específico, no consumo das refeições. Aplicação: 0 caso pode ser aplicado em cursos de administração e gestão, em níveis de graduação e pós-graduação. Principalmente, pode ser conduzido por docentes da área de empreendedorismo, estratégia, sustentabilidade e negociação.

Palavras-chave: redistribuição, alimentos, relação ganha-ganha, impacto social, negócios sustentáveis
\end{abstract}

\section{Abstract}

Context: Ecofood is a food redistribution platform that aims to reduce food waste on the planet, fight hunger and the emission of polluting gases. This is done by enabling the purchase of surplus food, but of excellent quality, at reduced prices through an application. Teaching objectives: The case makes it possible to understand the process of expanding digital platforms in the food sector and how impactful businesses can generate benefits for all stakeholders. Data sources: The case shows a real company that is going through an accelerated growth process. Its creators and managers started to discuss and discuss the expansion. The case was drawn up from primary and secondary sources. The names of the partners and the company have remained faithful throughout the history of the case. Contributions: From a social point of view, reducing food waste strengthens the fight against hunger and increases food security. On the other hand, it is necessary to show and realize that it is possible to have great financial gains by reducing the losses that occur with food, in this specific case, in the consumption of meals. Application: The case can be applied to administration and management courses, at undergraduate and graduate levels. Mainly, it can be conducted by teachers in entrepreneurship, strategy, sustainability and negotiation.

Keywords: redistribution, food, win-win, social impact, sustainable business 


\section{0 caso}

O ano de 2018 se iniciava e Rafael Moreno e Raphael Koyama, colegas de trabalho numa empresa de engenharia, debatiam sobre sustentabilidade, em função de um projeto que chegara ao escritório, com exigência de que ele fosse sustentável.

— Koyama, você viu as exigências do novo projeto? Querem que projetemos a obra, totalmente sustentável. O que você achou?

- Meu amigo, sei lá..., só se fala nisso atualmente, às vezes penso..., vale a pena gastar tanto a mais, assim como gastarão nesse projeto? Vai quase dobrar o valor...

- Rapaz, nem tudo é grana! Eu acho louvável essa preocupação, estão fazendo a parte deles para um mundo melhor. Isso é fantástico, essa preocupação com o meio ambiente, com as pessoas, o impacto que isso causará. Já sou fã desse grupo! - Declarou Rafael.

— Não sei, não tenho opinião formada ainda... - Permanecia reticente Koyama.

A conversa fluiu e o debate se estendeu para o assunto de desperdício no projeto que, de alguma forma, precisaria ser também pensado no projeto, e dali enveredou para a discussão sobre desperdício de uma forma geral. Rafael, criado em meio aos fogões e bancadas, já que sua família foi dona de uma rede de restaurantes e petiscaria, citou sua experiência e o que costumava ver ao final do dia:

- Rapaz... eu fui criado no meio de restaurantes, é de chorar ao ver a quantidade de coisas jogadas fora, comida boa, comida bem-feita, gostosa e saudável... é de cortar o coração. E o pior, tanta gente sem poder se alimentar bem... muita gente passando fome e muita gente que trabalha, ganha pouco, mora longe de casa e se alimenta mal ou mesmo se subalimenta, por não ter grana pra comprar comida fora de casa... é outro lado que comove. Você já viu o que esses trabalhadores do centro ali, que trabalham na rua comem? Eu nem chamo de almoço... É triste.

O bate-papo criou um desconforto. Naquela noite, Koyama dedicou tempo em uma busca sobre o assunto. Os dados e números sobre desperdício de alimentos o impressionaram, o que o levou a pensar na antítese: tanto desperdício e, ao mesmo tempo, tanta fome. A busca continuou e ele se deparou com dois aplicativos que chamaram sua atenção, a Too Good To Go, da Dinamarca e o Karma APP, da Suécia. Foi, então, que o seu lado empreendedor aflorou. Esses aplicativos, motivadores para os dois jovens empreendedores, eram plataformas de redistribuição de alimentos que estavam impactando a sociedade, cada um à sua forma, mas, no geral, buscavam unir o elo: a redução de desperdício e a facilitação de alimentação para pessoas carentes ou de baixa renda.

Passava de 1h30min da madrugada, mas sem hesitar, naquela hora, por meio de mensagem de telefone, Koyama enviou a ideia a Rafael:

- Meu velho, achei uma solução. Cara, vamos mudar o mundo?

- O que você está falando, são quase duas da manhã, temos todo aquele projeto para fazer amanhã, ou melhor, hoje! — Reclamou Rafael.

- Rafa, achei dois aplicativos (apps), plataformas, que unem dois lados necessitados. Pensa comigo... Sobra muita comida que é jogada no lixo pelos restaurantes e tem muita gente com fome ou se alimentando mal. Bom, a minha ideia é propor um aplicativo para que as pessoas procurem comida barata que possam pagar e que, normalmente, iria para o lixo.

- Como assim? - Indagou Rafael.

- Pensa... Se os restaurantes formassem marmitas com a comida que sobra diariamente e compartilhassem isso no app, e as pessoas, ao abrirem o app, vissem restaurante por restaurante, o que eles têm de marmitas, com preço menor, mas a mesma comida que o restaurante prepara... A sacada está aí..., eles entram, olham, escolhem e esperam chegar. $O$ operacional é assim: o restaurante $X$ tem oito marmitas de sete reais cada. Eu adquiro o voucher pelo aplicativo e apresento quando vou lá retirar. Vem comigo! Imagina, funcionários de obras, de grandes projetos e construções - que nós sabemos o que passam - reunidos, arrematam todas as marmitas de um restaurante. Acabou a má alimentação das pessoas e, ao mesmo tempo, para o restaurante é ótimo, porque faturam com o que iriam jogar fora, normalmente.

- Bom, até gostei da ideia!! Mas, se todo mundo fizer isso, ninguém vai comprar a comida, pois irão esperar "ficar na promoção". - Refletiu Rafael. 
- Não, não é prato feito, balanceado. É uma refeição com a comida que acabou não sendo vendida. Quem pode pagar, prefere escolher sua comida, ir até o ambiente do restaurante. Além disso, teremos a conscientização. Queremos acabar com o desperdício de comida no mundo e ajudar a alimentar as pessoas... As refeições seriam entregues ao final do expediente, depois que donos e funcionários já tenham feito a sua refeição. Todo o negócio é uma relação ganha-ganha: ganha o restaurante, ganhamos nós, ganha o mundo - Detalhou Koyama.

- Ah lindo..., mas estamos no Brasil, esqueceu?! Sempre darão um jeitinho... E cara, por favor deixa eu dormir, preciso de no mínimo seis horas de sono por noite... amanhã nos falamos.

Mas, ao contrário de todo receio, no dia seguinte, as conversas evoluíram. Koyama conseguiu convencer Rafael e os futuros sócios passaram a observar, primeiro, de forma informal, depois, com algumas pesquisas, a quantidade de alimentos que era descartada ao fim de cada expediente nos restaurantes da cidade. Após alguns meses de idas e vindas no projeto, a empresa começou a operar. Ambos deixaram seus empregos de engenharia e concentraram todos seus esforços na empresa que passou a se chamar Ecofood, totalmente focada para a sustentabilidade ecológica e social. $\mathrm{O}$ aplicativo foi lançado com o propósito de reduzir o descarte de alimentos por parte dos estabelecimentos do ramo alimentício. As suas operações iniciaram-se, especificamente, em julho de 2018, com um perfil de startup. A empresa tem sua sede no município de Londrina, cidade do norte do Paraná.

— Quem diria né... somos empresários... Empreendedores sociais... que louco isso, mas adorei a ideia. — Refletiu Koyama.

- Cara, mais do que isso, estamos fazendo nossa parte para um mundo melhor. - Idealizou Rafael.

Os sócios trabalharam na ideia, concepção e operacionalização do aplicativo e se dedicaram integralmente ao empreendimento. Em pouco tempo, o aplicativo decolou, cumprindo sua função social. Se, de um lado, a função social estava fluindo, de outro, a contraparte empresarial ainda era insuficiente. A monetização do trabalho não era satisfatória, pois a plataforma monetizava-se com uma pequena porcentagem sobre as marmitas vendidas, obviamente, não poderia ser muito, pois encareceria o preço do produto, desviando de sua função social.

\section{Ecofood: trajetória e atuação}

A Ecofood foi idealizada, em 2018, e suas operações se iniciaram em 2019. Trata-se de uma startup que já nasceu em um contexto voltado para sustentabilidade e tem por propósito reduzir o descarte de alimentos por parte dos estabelecimentos do ramo alimentício. A empresa tem sua sede no município de Londrina, cidade do norte do Paraná.

O app, disponível para as duas maiores plataformas de smartphones - Android e iOS - funciona como uma vitrine de mediação na relação entre estabelecimentos do ramo alimentício e consumidores. Os restaurantes, bares, padarias e demais estabelecimentos cadastrados disponibilizam determinadas quantidades de refeição no aplicativo em horários específicos. Como é o próprio estabelecimento que estipula as porções disponíveis, não existe possibilidade de a adesão do aplicativo competir com as operações triviais do restaurante. A cada venda realizada é uma refeição adquirida a um preço mais acessível, salvando uma fatia de alimentação de qualidade do desperdício.

Os consumidores ao acessarem a plataforma, podem selecionar as refeições, então compram os vouchers disponibilizados e vão até os estabelecimentos retirar a refeição ou os alimentos nos horários marcados. Cabe ressaltar que os estabelecimentos fornecem os produtos em excelente estado para consumo, não é nada diferente das refeições consumidas dentro do estabelecimento. Os usuários do aplicativo possuem a vantagem de pagar mais barato, beneficiando-se de uma refeição que iria, literalmente, para o lixo. Na Figura 1, é possível verificar a dinâmica do aplicativo.

Não é preciso ser um grande desperdiçador para se tornar parceiro da Ecofood. Os sócios citam um exemplo de uma confeitaria que disponibiliza dois vouchers de bolo a cada sábado, justamente com o intuito de que, mesmo quem se alimente deste bolo no sábado, o faça com qualidade, ou seja, no mesmo dia em que foi feito. Assim, na segunda-feira, há uma nova remessa produzida. A missão do Ecofood é "tornar vivo o sentimento nas pessoas de poderem contribuir com ações simples, mas nobres", a visão é "naturalizar a atitude ECO" e seus valores são: AmorECO; brilho nos olhos; liderança pelo exemplo; sustentabilidade nas ações; jeitinho brasileiro (Ecofood, 2021). 
Figura 1 - Funcionamento do aplicativo da Ecofood

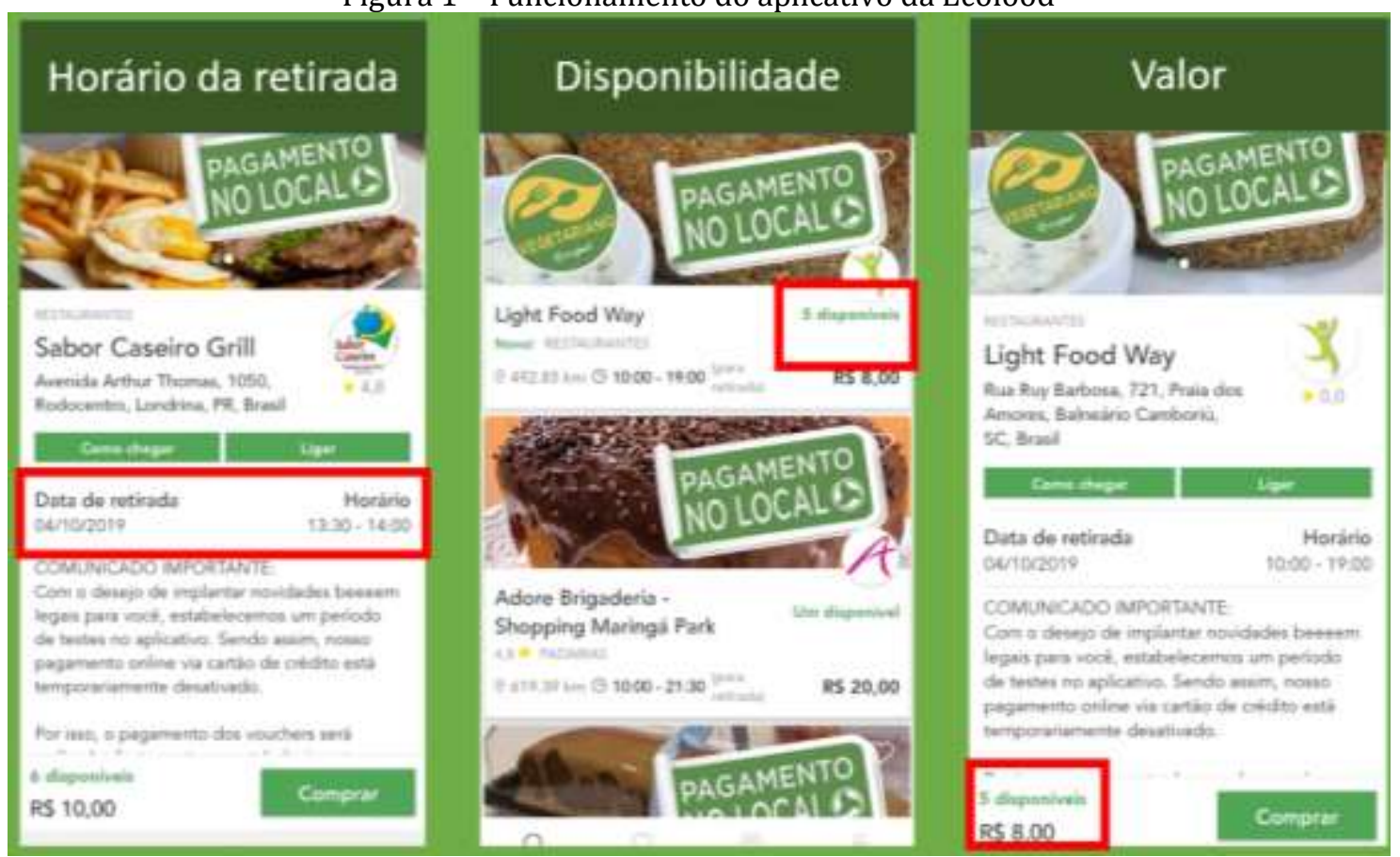

Fonte: Elaborado pelos autores (2021) com base na dinâmica do aplicativo.

Em seu site oficial, a empresa apresenta alguns dados interessantes a respeito do desperdício, ou melhor, sobre como a Ecofood o evitou. Exemplos são as 24.46 toneladas de comidas resgatadas, 44 . 387 refeições salvas e 88.77 toneladas de CO2 evitadas, sendo esses números crescentes, dia a dia (Ecofood, 2021). Hoje, conta com quase 130 restaurantes cadastrados e atende além de Londrina, outros 5 municípios da região.

Como resultado desse desempenho e do impacto que tem gerado, em março de 2019, a startup participou de um concurso com mais de 1.000 inscritos e foi uma das dez ganhadoras do prêmio de Rony Meisler, presidente do Movimento Capitalismo Consciente. 0 prêmio reconhecia o papel e atuação das empresas mais conscientes do país.

A criação da empresa partiu da observância de seus sócios-fundadores, Rafael Moreno e Raphael Koyama, acerca da quantidade de alimentos que era descartada ao fim de cada expediente nos restaurantes da cidade (Chiba, 2019; Paschoal, 2019). 0 caso ganhou repercussão regional e nacional, com reportagens publicadas em jornais e revistas, como o site do programa Pequenas Empresas Grandes Negócios (PEGN, 2019), Band News FM (Martiniuk, 2019), na Folha de Londrina (Chiba, 2019), no Londrinando (Paschoal, 2019).

Ainda, em 2019, contaram com o apoio da Cargill, quando foram selecionados no 1응 SDG Tech Awards Brasil, como prêmio, um bootcamp de inovação na Companhia e vão para Dinamarca em missão de negócios. A Ecofood também é parceira da ONG Banco de Alimentos (2020), a qual busca alcançar a sustentabilidade por meio de mudanças socioculturais, bem como realizar a ponte entre "os dois Brasis": o Brasil que passa fome e o Brasil que desperdiça alimentos todos os dias.

No mesmo ano de sua criação, a empresa começou a traçar planos de expansão. Sabendo que os negócios baseados em tecnologia são passíveis de ser gerenciados remotamente, abriu-se a oportunidade de avaliar possíveis cidades para parcerias e operações. As primeiras cidades a serem avaliadas foram Maringá, também no Paraná, e Balneário Camboriú, em Santa Catarina.

Em 2020, a empresa, assim como grande parte dos negócios do país, a Ecofood passou por um grande impacto devido às medidas restritivas impostas pela pandemia causada pela Covid-19, quando os primeiros decretos municipais fecharam os estabelecimentos por semanas. 0 negócio teve o seu volume de transações drasticamente reduzido, pois a ideia do aplicativo não conta com entregas feitas pelos aplicativos tradicionais para não comprometer a política de refeição barata.

Em função da queda acentuada da receita, a empresa decidiu acelerar uma ideia baseada na venda de "produtos para durar", que consiste na venda de produtos não descartáveis que acompanham as refeições. São canudos, copos, hashis e porta copos que podem ser adquiridos no aplicativo ou no site da 
empresa. Em 2021, após as incertezas iniciais causadas pela crise sanitária e o estabelecimento de diretrizes para operação de restaurantes, a plataforma recuperou o fluxo de transações e realizou expansão para três cidades, consolidando suas atividades em Santa Cruz do Rio Pardo - SP, Maringá - PR e Dourados - MS.

Hoje, os compromissos da empresa continuam sendo voltados para soluções que possam aliar desenvolvimento econômico e as questões sociais e ambientais de suas decisões. Além disso, a plataforma fortalece práticas e ações que não associem a empresa ao greenwashing, que no entendimento de Lyon \& Monterrey (2015), engloba uma gama de comunicações e ações que induzem as pessoas a adotarem crenças excessivamente positivas sobre o desempenho, práticas ou produtos e serviços de uma organização.

\section{Uma questão de continuidade e sobrevivência}

O tempo passou e os primeiros contatos com os restaurantes foram consolidados e ampliados, assim como a utilização do aplicativo pelos consumidores. Como o negócio apresentou sucesso rápido, algumas ideias começaram a surgir na cabeça dos sócios. Rafael e Koyama passaram a discutir então, a possibilidade de expansão das atividades da empresa para outras cidades da região Sul do país.

Havia ainda certa resistência por parte de Rafael, pois a startup não tinha completado um ano de atuação no mercado, mas seu sócio insistia nessa possibilidade. Durante uma dessas reuniões matinais, os empreendedores tiveram uma conversa sobre os próximos passos da operação:

— Você acha mesmo que chegou a hora de expandir? — Questionou Rafael. — Ontem mesmo estávamos falando e discutindo sobre as etapas do projeto e agora você fala que quer ir para outras cidades.

- Claro! Já temos maturidade suficiente para isso. Se demorarmos muito, outros concorrentes podem se apropriar da ideia e saírem na frente. Se ficarmos esperando, ficaremos para trás. A ideia é boa e vai pegar lá também. Aqui, já somos sucesso! — Confiante, alegou Koyama.

- Como assim? Maturidade com apenas um ano de atuação? Algo não está "batendo" nessa conta, Koyama. Ainda temos que recuperar o que investimos.

- Acredito que a maturação e o retorno desse segmento não sejam iguais às de um negócio convencional.

- Ponderou Koyama.

- Eu sei, mas precisávamos amadurecer mais a ideia aqui, conquistar mais usuários e parceiros. De onde vamos tocar a nova operação? Quem vai fiscalizar os padrões que estipulamos será garantido? - Agora, reticente era Rafael.

- Iremos tocar tudo daqui, montamos uma equipe que pode se conectar com a gente em momentos específicos e acompanhamos os demais processos por aqui. - Justificou Koyama.

- Não entendi!

- São novos tempos, Rafael. Podemos fazer tudo aqui do escritório. Sem muito investimento na nova cidade, dá para fechar negócio, prospectar clientes e parceiros sem precisar montar uma operação na cidade. Quem sabe alguns representantes... - Mencionou Koyama. - E sabe aquela história de que o que engorda o gado é o olho do dono? A meu ver, precisa ser repensada e rápido. No nosso segmento, a expansão se dá de modo diferente.

- Mas como pretende fazer isso? Não temos capital suficiente, mesmo que sejamos os pioneiros nesse segmento, não somos uma Uber ou iFood, que conta com um capital maior para expansão. - Ainda titubeava Rafael.

— Sim, eu sei, mas nós iremos fazer isso juntos. — Confiante, afirmou Koyama.

Nesse momento, um assunto delicado entrou em pauta na discussão. Koyama, entendendo o aplicativo como uma empresa que precisa gerar resultados financeiros, expôs sua visão para Rafael.

- Inclusive eu estava pensando nisso... temos que aproveitar esse crescimento, as pessoas usando o aplicativo para começarmos a fazer ele dar lucro... Precisamos monetizar.

- Mas Koyama, o aplicativo já se paga pelas porcentagens das vendas das marmitas, ele já faz isso... nosso foco é a responsabilidade social, a sustentabilidade, reduzir o desperdício, ajudar pessoas... Não estou te entendendo. - Questionou Rafael.

- Nós precisamos ir além... Temos uma empresa, precisamos ganhar dinheiro com isso. Deixamos nossos empregos, ganhávamos bem. Precisamos compensar isso, temos na mão uma oportunidade de unir o útil 
ao agradável.

- Mas Koyama, nosso propósito é outro..., queremos ajudar o mundo. - Comenta Rafael.

- Meu amigo, nós continuaremos a fazer isso! Minha ideia vem no sentido que, como nossa proposta é sustentabilidade, deveríamos colocar à venda produtos ecologicamente corretos, copos reutilizáveis, canudos de alumínio, hashi de acrílico, por exemplo. Nosso foco seriam estratégias de venda para o público final. Além disso, tentaremos vender nossos produtos com nossa marca para os restaurantes. Pensa... para nossos parceiros, seria interessante que eles tivessem a marca aliada a um aplicativo socialmente responsável, sustentável. Além do mais, continuaremos a proposta inicial, vamos continuar trabalhando contra o desperdício, mas aproveitamos essa comoção acerca da nossa marca e vamos aproveitar para aumentar nossa margem.

- Não sei, acho que pode ser mal interpretado... Podem pensar que estamos nos aproveitando da situação. Você sabe, o que não falta atualmente é a turma do politicamente correto, haters e afins, que não fazem nada e querem criticar. E essa crítica, às vezes, influencia as pessoas... vão dizer que praticamos greenwashing... Eu te entendo, Koyama, e, na verdade, não acho uma má ideia..., mas nossa proposta inicial era outra. - Avaliou Rafael.

- Eu sei, eu sei! Mas vamos sobreviver como? Dependendo de órgãos governamentais e organizações do terceiro setor que destinem premiações e verbas para nós? Esperar eles quererem investir em nós? Isso é muito incerto... A expansão em si já é uma tentativa de faturar mais, mas ainda é muito pouco. Precisamos pensar em ser gigantes, para que nossa operação realmente nos sustente financeiramente, por isso, precisamos de outras formas de renda.

- Como te falo, entendo sua preocupação, entendo seu ponto de vista, entendo sua necessidade, mas o que me preocupa - e muito - é se, nesse processo, a gente não desviará o propósito do nosso trabalho. O propósito era aliar nossa atividade com sustentabilidade, gerar impacto social e ser reconhecido por isso. Será que explorar comercialmente nosso aplicativo, vendendo produtos com nossa marca, é realmente coerente? - Veja bem, o objetivo do negócio era gerar impacto e não podemos ficar restritos à nossa cidade. Vamos gerar impacto e, ao mesmo tempo, ganhar dinheiro com isso... É uma recompensa pela nossa coragem, tomada de decisão e trabalho diário. Temos que, de alguma forma, fazer nosso esforço valer a pena, precisamos valorizar nossa ideia por meio de lucros.

Diante do desafio que se lançava, Koyama entendeu que não seria fácil mudar a ideia do sócio. Entretanto, a conversa, de certo modo, introduziu em Rafael alguma curiosidade sobre o que Koyama comentou. Mas, apesar do impasse, perguntas ainda ecoavam em suas cabeças: Como fazer? Por onde começar? Montar uma nova carteira de clientes sem estar presencialmente na cidade ou na região é possível? E, principalmente, mudar o foco inicial do aplicativo seria compreensível?

\section{0 dilema}

Enquanto Koyama já tinha em mente um projeto de expansão da Ecofood e, principalmente, a mudança da forma de faturamento, Rafael ainda se sentia um tanto receoso, temia que o negócio perdesse a identidade, fosse mal interpretado e o empreendimento fracassasse no meio do caminho. Estava claro que era preciso expandir, mas não era consenso que, para isso, fosse necessário mudar o foco, mesmo sem perder a missão. Logo, o impasse estava instaurado: manter-se como intermediário, em uma plataforma, que tem como objetivo aliar atividade com sustentabilidade, gerar impacto social e ser reconhecido por isso, mas com baixo faturamento; ou inserir a venda de produtos para o consumidor final e restaurantes, para ampliar a lucratividade, mas com o risco de ser mal interpretado? Como expandir e gerar lucro sem perder sua identidade? Qual caminho eles deveriam seguir?

\section{Questões para reflexão}

1) Até que ponto pode-se dizer que as atividades da Ecofood são uma experiência ganha-ganha entre os membros envolvidos na atividade do aplicativo? Existem possibilidades de potencializar essas relações? 2) Qual a possibilidade de as dimensões ambientais, econômicas e sociais também participarem dessa relação ganha-ganha? 0 que cada dimensão ganha com isso com base na experiência?

3) Quais outros caminhos poderiam ser viáveis, caso a decisão seja de manter a Ecofood como intermediária na relação? 


\section{NOTAS DE ENSINO}

As notas de ensino a seguir contêm os elementos da exposição teórica acerca dos temas que guiam este caso. Ademais, expõem os objetivos pedagógicos e as sugestões para o professor utilizar o conteúdo.

\section{- Fonte dos dados}

Este caso foi elaborado através de fontes primárias, por meio de entrevistas e comunicação direta com os sócios-proprietários da empresa Ecofood, bem como através de fontes secundárias, como o site oficial da empresa, notícias que continham o conteúdo referente a Ecofood e documentos indicados pelos sócios nas conversas. Os nomes dos sócios e da empresa se mantiveram fiéis em todos os momentos da história do caso.

\section{- Objetivos didáticos}

O caso tem como objetivo geral:

- Refletir sobre os benefícios do negócio da Ecofood para o estabelecimento, para o consumidor e para o aplicativo - a situação tríplice de ganha-ganha. Outros atores podem surgir durante a discussão, como a gestão de resíduos.

E como objetivos secundários:

- Demonstrar aos alunos a possibilidade de se estabelecer relações ganha-ganha em questões sociais e sustentáveis a partir do uso de tecnologias;

- Apontar as diferentes perspectivas na tomada de decisão de negócios sustentáveis;

- Indicar como plataformas locais e regionais podem se expandir mesmo com um aporte econômico restrito;

- Destacar as dimensões sociais e ambientais que costumam ser colocadas em um segundo plano com relação às práticas de sustentabilidade.

\section{- Sugestão de aplicação do caso}

0 caso pode ser aplicado em cursos de administração e gestão, em níveis de graduação e pósgraduação, principalmente, pode ser conduzido por docentes da área de empreendedorismo, estratégia, sustentabilidade e negociação. Outro campo que pode ser discutido, desde que bem problematizado, é na área de sustentabilidade e responsabilidade social corporativa.

Sugere-se ao professor começar a discussão do caso instruindo a classe a fazer uma breve reflexão com as perguntas dispostas após o dilema. Depois dessa reflexão individual, o professor pode iniciar perguntando à turma se Koyama conseguiria convencer Rafael da sua proposta. A classe pode, então, se dividir em dois grandes grupos: de um lado, alunos achando que sim e, de outro, alunos achando que não. As questões para discussão poderiam ser utilizadas como base para o debate em grupos. Após o período de debate focal, o professor, como motivador, pode iniciar um questionamento rápido acerca das razões pelas quais os alunos defenderam suas posições. É esperado haver uma alta taxa de discussão da classe, o que proporcionará um bom aquecimento e motivação para o debate sobre o dilema. Ao final, os grupos apresentam suas propostas, mas deixam claro que elas podem ser melhoradas com a participação de outros tópicos levantados na sala. Como fechamento, o professor relata as ações executadas pelos sócios até o momento, mostrando qual caminho tem sido mais utilizado como estratégia de longevidade da empresa Ecofood.

Figura 2 - Plano de aula indicado

\begin{tabular}{|l|c|}
\hline ATIVIDADE & TEMPO SUGERIDO \\
\hline Reflexão individual & 15 minutos \\
\hline Apresentação da discussão inicial & 30 minutos \\
\hline Formação de dois grandes grupos & 10 minutos \\
\hline Reflexão em grupo & 30 minutos \\
\hline Apresentação dos argumentos dos grupos & 40 minutos \\
\hline Fechamento do caso & 20 minutos \\
\hline
\end{tabular}

Fonte: Elaborado pelos autores (2021).

\subsection{Questões sugeridas para a discussão}

1) Até que ponto pode-se dizer que existe uma experiência ganha-ganha entre os membros envolvidos? 
Qual é o principal pilar que potencializa essas relações?

2) Qual a possibilidade de as dimensões ambientais, econômicas e sociais também participarem dessa relação ganha-ganha? 0 que cada dimensão ganha com isso com base nas atividades proporcionadas pela Ecofood?

3) Seria possível fazer do limão uma limonada? Ou seja, seria possível administrar políticas de gestão socioambiental, fortalecendo os resultados financeiros, ambientais e sociais, sem perder o intuito da criação da Ecofood?

\section{- Guia teórico para uso do caso}

0 desperdício e a perda de alimentos não são novidade na história. A diferença é que no passado suas razões não podiam ser controladas. A causa era associada às questões climáticas, à ausência de infraestrutura e de tecnologias e às condições de higiene inadequadas na manipulação dos produtos (Schneider, 2013). Na atualidade, o desperdício ocorre nas fases de produção, de processamento, na distribuição, bem como no consumo doméstico (Grosso \& Falsconi, 2018). Cerca de 14\% do alimento produzido é perdido entre a produção e a distribuição (FAO, 2020a), e, quando se analisa o nível de desperdício no consumo, esses números são ainda maiores.

No Brasil, a questão assume nuances mais contraditórias, pois o país apresenta uma das maiores produções de alimentos do mundo e figura entre as maiores economias do planeta. No entanto, sua posição diferenciada não possibilita acesso aos alimentos por uma parte significativa da população. Outro ponto é que entre a distribuição e o consumo residencial, o desperdício evidenciado seria suficiente para alimentar a população interna vitimizada pela fome (Porpino, Prente \& Wansink, 2015).

Essas constatações se tornam mais problemáticas em um momento em que a fome volta a ser destaque nas discussões internacionais. Estimativas de 2020 relatam que quase 690 milhões de pessoas (8,9 \% da população mundial) estão em situação de fome no mundo. Esses dados refletem o aumento de 10 milhões de pessoas no período de um ano (FAO, 2020a). A FAO ainda destaca que ações são necessárias, global e localmente, para maximizar o uso dos alimentos nas esferas da produção e consumo.

Nesse sentido, a introdução de tecnologias, soluções inovadoras (incluindo plataformas de comércio eletrônico para distribuição e sistemas móveis retráteis de processamento de alimentos), novas formas de trabalho e boas práticas para gerenciar a qualidade dos alimentos são essenciais para implementar comportamentos que possibilitem mudanças transformadoras (FAO, 2020b).

Considerando que a perda mundial de alimentos tem uma forte associação com as dimensões ética e ambiental, a atenção internacional refletiu-se sobre sua presença na Agenda 2030 para o Desenvolvimento Sustentável. A inclusão da perda de alimentos e da redução do desperdício nos Objetivos de Desenvolvimento Sustentável (ODS) reflete a gravidade desse problema e levou a maiores esforços para a sua redução (FAO, 2019).

O Nobel da Paz de 2020 foi para o Programa Mundial de Alimentos (PMA), a maior agência das Nações Unidas, por seus esforços no combate à fome. Fica claro que o desperdício vai contra os princípios de sustentabilidade, e, dentre outras preocupações, busca formas mais adequadas de lidar com as questões dos recursos. Várias instâncias, no âmbito nacional e internacional, como distintas esferas governamentais e do setor privado têm discutido formas e metodologias para inserir e propagar os princípios de desenvolvimento da sustentabilidade e do desenvolvimento sustentável (DS) (Lima, 2016).

Distintas áreas do conhecimento e muitos autores, dentre os quais Sachs (2008), Strezov, Evans \& Evans (2017), Kelly, Sirr e Ratcliffe (2004), Buarque (2008), Seghezzo (2009), Schaltegger, Beckmann \& Hockerts (2018), Albuquerque (2015), Hufnagel, Reckling \& Ewert (2020) tratam o DS como um tipo de desenvolvimento que atende múltiplas dimensões. Além disso, caracteriza-se pela busca de equilíbrio de questões econômicas, ambientais, políticas, socioculturais, entre outras. A Figura 3 destaca as dimensões presentes no DS, suas características e critérios para serem propagadas e fortalecidas.

Figura 3 - Dimensões, características e critérios do desenvolvimento sustentável

\begin{tabular}{|c|c|l|}
\hline DIMENSÃo & \multicolumn{1}{|c|}{ CARACTERÍSTICAS } & \multicolumn{1}{c|}{ CRITÉRIOS } \\
\hline & $\begin{array}{c}\text { Social e hu- preocupação com o bem-estar da população, } \\
\text { mana } \\
\text { com a promoção da cidadania e a melhoria na } \\
\text { qualidade de vida. A motivação é reduzir signi- } \\
\text { ficativamente as diferenças sociais. }\end{array}$ & $\begin{array}{l}\text { Acesso e melhoria da educação, formação, nutrição e } \\
\text { saúde; distribuição de renda para a inclusão social e o } \\
\text { reforço do mercado consumidor interno; } \\
\text { Qualidade das relações de trabalho, ampliação do pa- } \\
\text { pel das mulheres na sociedade e as economias social e } \\
\text { solidária. }\end{array}$ \\
\hline
\end{tabular}




\begin{tabular}{|c|l|l|}
\hline DIMENSÃo & \multicolumn{1}{|c|}{ CARACTERÍSTICAS } & \multicolumn{1}{c|}{ CRITÉRIOS } \\
\hline Econômica & $\begin{array}{l}\text { Louva-se a responsabilidade social corporativa, } \\
\text { com a geração de emprego sobreposta e gera- } \\
\text { ção de renda. Ao papel governamental, as ações } \\
\text { vão no sentido de diminuir os custos sociais e } \\
\text { ambientais com alocação eficiente de recursos. }\end{array}$ & $\begin{array}{l}\text { Desenvolvimento econômico intersetorial equili- } \\
\text { brado, com apoio às micro e pequenas empresas e co- } \\
\text { operativas locais; } \\
\text { Segurança alimentar e a diversificação e qualidade } \\
\text { produtiva no território com desenvolvimento técnico } \\
\text { e científo dos instrumentos de produção. }\end{array}$ \\
\hline $\begin{array}{c}\text { Ambiental e } \\
\text { ecológica }\end{array}$ & $\begin{array}{l}\text { É necessário equilíbrio entre o desenvolvi- } \\
\text { mento social e a preservação da natureza. Por- } \\
\text { tanto, devem-se aplicar tecnologias limpas que } \\
\text { permitam a gestão ambiental e dos recursos } \\
\text { com inutilização no nível mínimo. }\end{array}$ & $\begin{array}{l}\text { Proteção do potencial de capital e proteção de recur- } \\
\text { sos naturais renováveis; } \\
\text { Limitação e criação de alternativas para uso de recur- } \\
\text { sos navováveis. }\end{array}$ \\
\hline
\end{tabular}

Fonte: Elaborado pelos autores com base em Sachs (1993; 2002; 2008) e Albuquerque (2015).

No mundo corporativo, a sustentabilidade é vista sob um paradigma ganha-ganha, que se caracteriza por defender que os aspectos econômicos, ambientais e sociais de sustentabilidade corporativa sejam - pelo menos parcialmente - harmoniosos uns com os outros e pela gestão procurar identificar os casos em objetivos econômicos, ambientais e sociais realizados simultaneamente (Hahn et al., 2010). Enquanto não há evidências crescentes de que relações ganha-ganha sejam unanimidade, podem existir argumentações, em determinadas condições, que sustentam que a suposição de que estes três princípios são, na sua maioria, harmoniosos uns com os outros, é um pouco simplista, dada a natureza complexa e multifacetada da sustentabilidade. Consequentemente, fechar os olhos para os trade-offs e conflitos em sustentabilidade corporativa leva a uma perspectiva limitada das contribuições. Em situações de tradeoff, é impossível alcançar dois ou mais desejáveis objetivos simultaneamente. Em vez disso, tomadores de decisão precisam pesar uma perda em pelo menos uma dimensão de encontro a um ganho em outras dimensões (Hahn et al., 2010).

\section{- Fechamento do caso}

Por se tratar de um caso real, o fechamento poderá ser feito com uma apresentação das principais sugestões e hipóteses elaboradas pelos alunos e endereçadas à empresa. Inclui-se o professor, no papel de moderador, para intervir quando a discussão ficar mais acalorada. Uma vez que o dilema exposto no caso é recente, a empresa ainda não executou na totalidade a tomada de decisão, seja por uma expansão, seja pela escolha da venda de produtos ecológicos. Cabe aos alunos, enquanto provedores de soluções, que apresentem as melhores práticas para o exposto no caso.

Além do já sugerido, o professor pode refletir com a classe sobre os impactos positivos em conservação de solo, energia, água e recursos utilizados na agricultura, além da diminuição de poluição atmosférica, por exemplo, como motivadores da expansão e da atividade de venda de produtos ecológicos. Os alunos também podem navegar em outras literaturas que ajudem, de maneira indireta ou até diretamente, na apresentação de soluções para o dilema. Exemplos disso são: gestão de marcas, gestão de operações, gestão de projetos e impacto social.

\section{Referências}

Alburquerque, F. (2015). Enfoque, estratégias e información para el desarrollo territorial: los aprendizajes desde ConectaDel. Buenos Aires: BID-FOMIN, 2015. Disponível em: < http://www.conectadel.org/biblioteca-2-2/?did=364l> Acesso em 29 jul. 2020.

Buarque, S. C. (2008). Construindo o desenvolvimento local sustentável (4a ed). Rio de Janeiro: Garamond. Chiba, M. F. (2019). Londrinenses lançam aplicativo contra o desperdício de comida. 22 fev. 2019. Disponível em: https://www.folhadelondrina.com.br/economia/londrinenses-lancam-aplicativo-contradesperdicio-de-comida-1027365.html. Acesso em: 01 out. 2020.

Ecofood. (2021). Website. Disponível em: https://www.ecofood.com.br/. Acesso em: 3 mar. 2021.

FAO - Food and Agriculture Organizations of The United Nations. (2019). The State of Food and Agriculture 2019. Moving forward on food loss and waste reduction. Rome. Licence: CC BY-NC-SA 3.0 IGO. Disponível em: http://www.fao.org/3/ca6030en/ca6030en.pdf. Acesso em: 01 mar. de 2021.

FAO - Food and Agriculture Organizations of The United Nations. (2020a). The State of Food Security 
and Nutrition in the World 2020. Transforming food systems for affordable healthy diets. Rome, FAO. Disponível em: http://www.fao.org/documents/card/en/c/ca9692en. Acesso em: 01 mar. de 2021.

FAO - Food and Agriculture Organizations of The United Nations. (2020b). International Day of Awareness of Food Loss and Waste. Disponível em: http://www.fao.org/international-day-awareness-foodloss-waste/en/. Acesso em: 01 mar. de 2021.

Grosso, M., \& Falasconi, L. (2018). Addressing food wastage in the framework of the UN Sustainable Development Goals. Waste Management \& Research, 36(2), 97-98.

Hahn, T., Figge, F., Pinkse, J., \& Preuss, L. (2010). Trade-offs in corporate sustainability: You can't have your cake and eat it. Business Strategy and the Environment, 19(4), 217-229.

Hufnagel, J., Reckling, M. \& Ewert, F. (2020) Diverse approaches to crop diversification in agricultural research. A review. Agronomy for Sustainable Development. 40 (14), 1-17.

Kelly, R., Sirr, L., \& Ratcliffe, (2004). R. Futures thinking to achieve sustainable development at local level in Ireland. Foresight, 6(2), 80-90.

Lima, C. E. (2016). A Institucionalização da Temática Sustentabilidade em Pós-Graduações Stricto Sensu em Administração no Brasil. 181 p. Dissertação (Mestrado em Administração) - Universidade Estadual de Londrina, Londrina.

Lyon, T. P., \& Montgomery, A. W. (2015). The means and end of greenwash. Organization \& Environment, 28(2), 223-249.

Martiniuk, T. (2019). Aplicativo de celular ajuda a reduzir o desperdício de comida. 2 jul. 2019. Disponível em: https://bandnewsfmcuritiba.com/aplicativo-de-celular-ajuda-a-reduzir-o-desperdicio-de-comida. Acesso em: 07 set. 2020.

ONG Banco de Alimentos. (2020). Website. Disponível em: https://bancodealimentos.org.br/o-que-fazemos. Acesso em 24 de set. 2020.

Paschoal, M. (2019). Startup londrinense ajuda a salvar toneladas de comida do desperdício. Disponível em: https://londrinando.com/post/588/startup-londrinense-ajuda-salvar-toneladas-de-comida-dodesperdicio. Acesso em: 01 out. 2020.

PEGN. (2019). De robô garçom ao dízimo na maquininha: startups mostram soluções em evento. 24 jul. 2019. Disponível em: https://revistapegn.globo.com/Startups/noticia/2019/07/de-robo-garcomao-dizimo-na-maquininha-startups-mostram-solucoes-em-evento.html. Acesso em: 05 set. 2020.

Porpino, G., Parente, J., \& Wansink, B. (2015). Food waste paradox: antecedents of food disposal in low income households. International Journal of Consumer Studies, 39(6), 619-629.

Sachs, I. (1993). Estratégias de transição para o século XXI: desenvolvimento e meio ambiente. São Paulo: Nobel.

Sachs, I. (2002). Caminhos para o desenvolvimento sustentável. Rio de Janeiro: Garamond.

Sachs, I. (2008). Desenvolvimento: includente, sustentável e sustentado. Rio de Janeiro: Garamond.

Schaltegger, S., Beckmann, M., \& Hockerts, K. (2018). Sustainable entrepreneurship: creating environmental solutions in light of planetary boundaries. International Journal of Entrepreneurial Venturing, 10(1), 1-16.

Schneider, F. (2013). The evolution of food donation with respect to waste prevention. Waste Management, 33(3), 755-763.

Seghezzo, L. (2009). The five dimensions of sustainability. Environmental Politics, 18(4), 539-556.

Strezov, V., Evans, A., \& Evans, T. J. (2017). Assessment of the Economic, Social and Environmental Dimensions of the Indicators for Sustainable Development. Sustainable Development, 25(3), 242-253. 